the special attention of those interested in asylum work to the excellent and elaborate thesis above referred to. It is, I think, an unusual and a valuable example of the combination of clinical and pathological investigations.

In the case under consideration the small weight and under-development of the brain are noteworthy and it would have been interesting to have had these referred to, as also the relative thickness of the cortical layers in the case previously described. The cortical measurements given by Dr. Bolton show a wasting of nearly 27 per cent., mostly in the pyramidal layer ${ }^{2}$ which contains the highest association neurons and upon the integrity of which the most advanced needs of the individual depend-those needs based upon reason and intelligence, those which involve attention, comparison, and judgment, and which result from the interpretation. collection, and elaboration of incoming sensations arriving on the "platform" of the granular layer. The least wasting occurs in the polymorphic layer which Dr. Watson has shown to be related to the lower functions of the organic life, such as seeking for shelter, hunting for food, or those controlling the lower instincts, and it is only diminished in pronounced mental disease when the habits become degraded. The pyramidal layer has been shown by Dr. Bolton ${ }^{3}$ to be directly related to the mental capacity and power of the individual. It is under-developed in amentia, is well repre sented in persons of high mental grade, and is, in the latter class, wasted proportionately to the degree of dementia caused by a degeneration of the neuronic elements in this layer.

As to Huntington's chorea, its pathology is hitherto not definitely ascertained. Some observers have ascribed the symptoms to vascular changes leading to hyperplasia of glia tissue, the neurons being secondarily affected. Others uphold a primary degeneration of the nerve elements, interstitial changes being secondary and due to the chronicity of the process. Its affinity with general paralysis may suggest that it is itself a pre-senile condition affecting the higher neurons, the pyramidal and Betz's cells, through a vicious organisation-some genetic deficiency of power to survive, a "hereditary malformation" becoming a locus resistentia minoris. We know that alcohol may select to make its ravages evident in some perzons by cirrhotic changes, in some also by neuropathic changes, and in others by the psychopathies. In some persons decay is indicated by va-cular changes, in others it is indicated primarily in the nervous system. We appreciate that in every tissue there is a certain inherent tendency to evolve towards a higher state of development or towards perfectibility in regard to the environment, but this perfectibility is accompanied-as a set off-by diminished durability. The more highly developed the neuron the more deficient it is in durability; the less highly developed the greater the durability. We are acquainted with cases of juvenile general paralysis in which slight stress causes little injury and they linger on for long periods, and we may contrast with these cases occurring in highly developed and capable persons where great and severe stress has led to rapid deterioration and degeneration when once this "breaking strain" has been reached. What determines the tendencies to dissolution we do not know, for hitherto we have but little knowledge of the recessive or dominant characteristics which determine hereditary tendencies in the different structure of the body. We may further instance the parellelism of general piralysis and Huntington's chorea; both are progressive and fatal and both are associated with some form of paralysis, and it might not be inappropriate to include the paralysis accompanying Huntington's chorea in that group of cases described as "pseudo-general paralysis"-a term applied by Fournier, and referred to by Dr. T. B. Hyslop, ${ }^{4}$ as including ordinary general paralysis with remissions, also paralysis, more or less general, which may result from, or follow, alcohol, lead, or syphilis.

I am aware that the suggestion of pseudo-general paralysis is open to a retort from the logical mind that a thing is or is not, and that a disease is either general paralysis or it is not, but as clinicians we know that there are a number of atypical forms which for want of exact knowledge are most conveniently and expressively grouped as such. Whilst not personally subscribing to this somewhat comprehensive and inclusive classification of ge neral paralysis, and whilst recognising the variety of men'al affections accompanying

2 Archives of Neurology, p. 607, Case 19, Fig. 21

4 Transactions of the Medical Society, vol. xxvi true general paralysis, one's own experience can relate the as-ociation of mental deterioration with such cases as Friedreich's hereditary ataxia with choreiform movements, paramyoclonus multjplex, and some of the spinal system lesions (amyotrophic lateral sclerosis, bulbar pdralysis, and chronic muscular atrophy) which at infrequent intervals are met with in the larger asylums for the insane.

It is only by such records as that furnished by Dr. Peachell that we shall succeed in further grouping the many varieties referred to as pseudo-general paralysis. In a recent report of all the nervous and mental cases that have come under treatment in one year in the Central Municipal Hospital for the city of Dresden, the proportion of cases of Huntington's chorea was, I believe, only three, but I speak from memory. In the statistics of St. Bartholomew's Hospital, London, for 1904 th $*$ re are 64 cases of chorea, seven cases of insanity, but none indexed under the term Huntington's chorea. My own experience of over 10,000 male and female insane persons admitted into the London County Asylum at Claybury leads me to believe that this variety, excluding senile chorea, does not occur in asylums more often than about once in every 3000 cases-if as frequently.

Claybury.

\section{SOME REMARKS ON THE PREVENTION OF APPENDICITIS ${ }^{1}$ \\ BY W. J. TYSON, M.D. DURH., F.R.C.P. LOND. F.R.C.S. ENG., \\ HONORARY PHYSICIAN TO THE FICTORIA HOSPITAL, FOLKESTONF.}

Is bringing forward this subject before our societ, I think that some explanation is due to its members. In the first place, it has been discussed very fully of late; and in the second place, at first sight it may appear to have little to do with balneology. As my paper progresses I hope to give an answer to both statements. I think that there can be little doubt that appendicitis has much increasel of late years. Although many years ago cases of appendicitis were almost invariably put down as peritonitis, yet these peritonitic cases were less numerous than we meet with to-ilay. The type of case I believe has also changed, as in many other diseases, for the so-called simple or medical c ses we see less frequently than we used to. How this increase in number and alteration in type of cases have been brought about I hope to show later.

Before passing on to the clinical aspect of my paper it is well to say that there st'ms no doubt that the real starting point of the appendicular peritonitis is the presence of the bacillus coli communis in the appendix : yet this statement requires an explanatory note, for the above bacillus is always present in large numbers through the whole alimentary canal from the mouth to the anus: again, it varies greatly in its virulency. It is only when the bowel becomes the seat of any morbid change that the bacillus, so to speak, comes into play. Thus any change brought about in the bowel by constipation, diarrhoea, obstructed bowel, or congestion of the bowel becomes of immense importarce. Thus it seems that for an a:tack of appendicitis to occur there must be some lesion of the appendix to allow the escape of the bacillus and the bacillus must be in a state of virulency. Ordinary or simple catarrh of the appendix is evidently of common occurrence. Postmortem examinations show this. It generally leads to no symptoms and is not often clinically diagnosed. But there is a further stage of the trouble in which more or less inflammatory material is thrown out. This material maf go on to the formation of pus or be entirely absorbed.

Coming now to the practical or clinical side of our subject. everyone must at once be struck with the change of mind which has taken place in respect to the treatment of appendicitis. A few years ago all cases of appendicitis were admitted into the medical wards and treated by the phr. sicians. Now surgeons seem to claim these cases and all writers and speakers of to-day when discussing the subject of appendicitis refer to it almost entirely as requiring surgical treatment. This was particulal ly brought out at a meeting of the Royal Medical and Chirurgical

1 A paper read before the British Balneological and Climitligical Society on Dec. 7 th, 1905 . 
Society on Feb. 28th last when Sir Frederick Treves opened the discussion on the Subsequent Course and Later History of Cases of Appendicitis after Operation. Although the terms of the title of the discussion practically precluded the preventive or medical aspect of the subject, they nevertheless showed the trend of the feeling of the profession at the present time on this subject-viz., the surgical side, and practically ignoring the preventive or medical part. It is because I believe that this latter part of the above has been forgotten of late that $I$ bring it forward for your consideration this afternoon. I maintain that the purely surgical treatment of this disease, although, of course, right in its proper place, is treatment at the end of it; and all scientific and sound treatment of disease should aim at the prevention of disease or treatment in its very early stages. There is always a difficulty in discussing, especially with the lay public, the two great lines of treatment-(1) the preventive, and (2) the surgical; the former method can hardly be appreciated by the patient, for the disease has not yet come on ; there is no pain, sickness, or general feeling of illness. But in the advanced stage of the disease, in which an operation has relieved all the above symptoms, the patient is not likely to forget the great benefit received. In other words, it is very difficult to get carried out rules of diet, exercise, \&c., in order to prevent a disease, however serious, which the patient knows nothing about, and of the consequences of which he is entirely ignorant. Still, I maintain, if this disease is to be stamped out or, at any rate, brought under control, the real clinical causes of it must be studied and much more attention must be paid to the carrying out the rules by which we think the disease can be avoided.

I believe that the most prominent and active cause of appendicitis is constipation, a lodgment of undigested matter or fæcal masses in the bowel. It is often very difficult to decide on the presence of constipation, for the daily evacuation is not sufficient to settle this point. In those extreme cases in which patients come to us saying that they are suffering with diarrhoea, on rectal examination the lower bowel may be discovered to be entirely blocked up with hard masses of fæces ; but apart from these there may exist hard frcal lumps in the hepatic, splenic, or sigmoid flexure of the colon, and even in the small bowel, with a daily natural stool. I have on two occasions suffered from acute attacks of appendicitis, at an interval of a twelvemonth, both of which I traced to constipation. The cause of the second attack was most clear to me. I was travelling by quick stages along the south coast of France visiting the various health resorts in that neighbourhood. My bowels had been confined for four days and on the fifth my attack commenced and lasted for eight days. It is the experience of many patients that when the bowels have not been opened an attack of appendicitis is apt to occur. I think that our ancestors and the old physicians and apothecaries insisted much more strongly on the need and importance of regular and thorough bowel action than we do at the present day. The regular dosage with salts and black draught had much more to do with the prevention of intestinal toxæmic conditions than perhaps we even to-day are prepared to admit. Practitioners in those far-off days had more time to study clinically the symptoms of disease than the over-wrought student and precise physicians of to-day. Men in those days were great observers and they noticed that free stools kept the head clear and the body cool.

Now there are a good many conditions which have increased of late years which are more or less associated with constipation directly or inäirectly, such as oral sepsis, excessive and unnatural eating, as seen in our modern hotels, unsuitable foods, alcoholism in its various forms, weakened abdominal muscles, and wrong method of stooling; each of these requires some notice. "Defective masticating teeth are exceedingly common among the subjects of this disease, and especially among those who have passed the period of youth. Over and over again it would appear as if the want of proper and efficient teeth had been the direct cause of the attacks. Such patients often bolt their food and such meat as they eat can hardly reach the stomach in a condition fit for complete digestion. The bolus passes into the bowel still ill-digested. It fails to stimulate normal peristalsis, it is prone to lodge in the great receptacle-the cæcum-where it decomposes and if there be any existing lesion of the appendix must tend to encourage the morbid change." (Treves.)

In connexion with this question of the teeth I have often wondered why dentists have not paid more attention to the prevention of decay. Surely something might be done to prevent the almost universal decay of teeth that we now witness in all classes of the community and at all ages. We are always hearing of the bad results, and in some cases apparently very serious consequences, of oral sepsis, and yet stopping the teeth or their extraction seems at present the only remedy, forgetting that no artificial substitutes in the mouth can fully take the place of sound teeth naturally fixed. I also might refer at this stage of my paper to the present faulty mastication which now necessarily takes place with the soft artificial foods which are in vogue. This has been prominently brought forward and constantly urged by one of our Fellows, Dr. Harry Campbell. The full significance and the evil resulting from this mode of feeding primarily as regards gastric and intestinal digestion, and secondarily as regards the general system of the patient, are not to-day fully appreciated.

Coming now to the question of food, there can be little doubt that a great change has come about in our methods of eating, also in the quality and quantity of food we take. Personally, I cannot help thinking, and many hold this opinion, that the enormous amount of iced foods, in the shape of meat, fish, game, \&c., which are now taken plays an important part in many of our intestinal troubles. The above custom seems at present a necessity, and it seems little use to say very much about it. Yet for a long time have thought that there are decided dangers connected with the iced food traffic. Then again, as a rule, I think that nearly all of us are eating too much, too quickly, and not taking sufficient rest after the meals. It is not a fair argument to say that our ancestors ate as much, for it must always be remembered that they lived and exercised much in the open and fresh air, whilst many people to-day who eat most take. little or no exercise. Again, the modern table dhote dinner, as taken by the well-to-do people, is not favourable for peace and quietness among the contents of the digestive canal, nor can the present state of the knowledge of cookery among the poorer classes be considered conducive to their well-being. When the question of feeding is more carefully and systematically considered I believe that it will be found that it plays an important part in intestinal inflammation; also, apart from the quality and quantity of the food taken. irregularity of eating tends to set up gastric and intestinal irritation, and conceivably inflammatory conditions, such as appendicitis. Commercial travellers seem more liable to the foregoing conditions than other people.

Another point worth considering is the present method of stooling, and also the little use we make now of our abdominal muscle for the thorough expulsion of fæces and flatus. The old-fashioned and natural method of stooling on the ground, with the thighs flexed on the abdominal walls, so that in straining the inguinal and femoral canals are practically closed, has now gone out of fashion, and the modern unscientific, though comfortable, method is substituted for it. I believe that the former method of stooling is made more conducive to the thorough emptying of the bowel and therefore less likely for obnoxions and poisonous materials to be left behind. I am glad to see that there are already in the market some water-closets made which to a great extent carry out the natural methods. Again, the stays as worn by women in the present day must more or less weaken the expulsive action of the abdominal muscles. The practice of kneeling down, bringing the buttocks in contact with the heels, and the anterior chest wall in contact with the thighs, three or four times every morning, is a good and beneficial exercise, one which I have practised myself for some time past and recommended it to others.

In coming now to the part played by climatology and balneology in reference to the prevention of intestinal diseases we as a society are particularly interested. The question of climate and the various uses of mineral waters have been considered for many centuries, long before the Christian era. These waters are scattered in abundance throughout the whole continent of Europe and have more or less been systematically used by all classes of people and for many diseases. It has often been said that the people who need these waters-I am referring just now to those that are taken internally-do so on account of the excessive eating or indigestible food which they have indulged in previously to the treatment by balneology. This may be true in some cases, but I am sure that the custom of drinking special waters and of bathing is far too prevalent a custom to think that all these thousands of people who wash themselves inside and outside have over-eaten. To my mind 
1834 The LaNomt,] DR. R. W. PHILIP : RAW MEAT aLIMkNTATION IN TUbERCULOSIS. [Dec. 23, 1905.

this exceedingly common continental custom of "water" drinking" periodically and regularly must have had a very beneficial effect in the cure and the prevention of many intestinal diseases. These waters, existing in great varieties in great numbers of places, in great abundance, of various temperatures, and in different climates, seem to me to have a purpose that we in England have scarcely recognised or appreciated. We possess in our own country most valuable waters. It is not my purpose to describe these, which 1 think will be more fully understood and scientifically given when their raison d'être is understood. In these days of strife and stress, living, as most of us do, in towns, our habits tend more and more to be sedentary. The internal organs under this mode of living are apt to get clogged and to work heavily, and unless they get unloaded by some means the system suffers. I can hardly imagine anything more beneficial to the economy of the body than a course of waters suitably taken at one of our bathing resorts.

believe the regular washing out of the intestinal canal would do much to prevent a large number of cases now known as colitis and appendicitis.

I have avoided quoting cases in support of views expressed in this paper; it would take too long and probably be wearisome to you. Every kind and form of appendicitis are daily recorded. For the last 25 years it has fallen to my lot to see both in hospital and private work a large number of the above. A large number have required immediate operation, but a larger number have recovered under medical treatment. The title of my paper precludes the later or surgical aspect of the subject. It almost entirely deals with the prevention of the disease. Still, I see and read that there is a strong tendency, not so strong as it was, I think, to ignore the treatment of the early strge of the disease, at which time I believe that much good can be done by suitable and timely treatment.

What I have tried to bring out in this paper and wish the profession earnestly to consider is some methods or modes of treatment which will prevent to a great extent this now common disease of the appendix and also allay the morbid fear about the disease which is unhinging a large number of nervous people. I feel that a great deal more might be done than is being carried out to stamp out this disease. The operation that is constantly being done cannot be considered the true scientific treatment, although absolutely necessary in many cases when the disease is far advanced. My paper is essentially a clinical one and I do not claim for it any true scientific standpoint. Yet many of the best methods of treatment, I may also say most, have been discovered experimentally, before they have been explained scientifically. To give two examples. Ague was stamped out in Romney Marsh by careful and systematic drainage, long before the real cause of it was even thought about. The drainage disturbed and upset the mosquito and then the ague lessened and gradually disappeared. The giving of quinine was only a passing phase in the evolution of the treatment of the disease, although a most beneficial and comfortable crutch; quinine never lessened the amount of ague, although it modified the attack. Once more the operation of removal of the tongue for cancer has been one of the most unsatisfactory ones in the whole range of surgery. Clinically, this fact has been known for many years, but now it has been clearly demonstrated by Mr. G. L. Cheatle that almost invariably there is present in the genio-hyoid and the genio-hyo-glossus muscles cancer growth which is not touched at all in the ordinary operation for the removal of the tongue. Some day, before long, 1 hope we shall be able to demonstrate conclusively the exact cause and method of an appendicular attack. In the mean time, my experience leads me to think that some such view as I have attempted roughly to give you in this paper will partially explain the increasing number of cases of appendicitis that we meet with to-day.

Folkestone.

The After-Care Assoctation.-The council of the After-Care Association earnestly appeals for gifts of money or clothes to assist poor persons discharged recovered from asylums for the insane and for donations and subscriptions to carry on and to extend the work. Branches have now been formed in connexion with asplums in various parts of the country. Contributions will be thankfully received by the secretary, Mr. H. Thornhill Roxby, Church House, Dean's Yard, Westminster, London, S.W. The bankers are the Union of London and Smith's Bank, Argyll-place, Regent-street, W.

\section{ON RAW MEAT ALIMENTATION IN TUBERCULOSIS. ${ }^{1}$}

BY R. W. PHILIP, M.A., M.D. EDIN., F.R.S. EDIN., SENIOR PHYSICTAN TO THE ROYAL VICTORIA HOSPITAL FOB CONSUMPTION, EDINBURGH.

THE systematic use of raw meat in the treatment of taberculosis is not a new proposal. The method has had able exponents. I would mention more particularly in France Richet and Héricourt, who have submitted cogent evidence in support of the system. Notwitbstanding, the treatment seems to have been received less favourably, perhaps less seriously, than its importance warrants. Certainly its adoption has been less general than its results wculd lead us to expect. The purpose of the present paper is to submit a brief summary of experience extending over a good many years in the treatment of tuberculosis by means of systernatic alimertation by raw meat in one or other form.

From the clinical standpoint one of the earliest in dications of invasion by tuberculosis is the sense of muscular fatigue experienced by the individual attacked. This initial teeling of languor and lack of ene:gy remains a more or less persistent feature throughout, becoming intensified with the progress of the disease. In keeping with this there is quick!y determined an atrophy of muscular tissue frequently out of proportion to the loss of adipose tissue. The skeletal muscles waste conspicuously. Myotatic irritability to direct percussion is increased. Wasting of skeletal muscles is associated with wasting of the heart muscle, the muscular wall of the anteries a d the muscular wall of the gastro-intestinal canal. The latter finds it clinical expression doubtless in the rapid, feeble pulse and defective reristalsis. A similar change in relation to the skeletal muscles may be traced in bovine and avian tuberculosis, where the muscles may become enormously wasted, while large collections of fat remain present in connexion with the abdominal viscera. These considerations seem to support the view which on experimental grounds I submitted in 1887-viz., that the toxin of tuberculosis is especially a muscle poison and that the ultimate cause of death in uncomplicated pulmonary tuberculosis lies in poisoning of the heart muscle.

Theorising on such points I was led a good many years ago to practise raw meat alimentation in tuberculosis. The results obtained were so satisfactory that I have conticued the method ever since in much the larger proportion of my cases, both in hospital and in private. The striking researches of Richet and Héricourt placed the method of raw meat alimentation (zomotherapy) on a scientific basis. They found in the case of dogs inoculated artificially with tuberculosis that all such animals fed in the ordinary way speedily underwent a progressive emaciation while animals fed on raw meat in one or other form, in place of emaciating, put on considerable weight. They found that the muscle juice freshly expressed from the meat was as efficacious as the meat itself. Cooked meat was of practically no value.

Mode of exhrbition.-It must be kept in view that in order to be effective the alimentation by raw meat must be systematic and continued. Such alimentation is not a mere variation in the patient's dietary to suit his varying humour or caprice. It is a therapeutic procedure determined by the patient's needs in the light of clinical and experimental observation. Accordingly the form of exhibition and dose ought to be regulated in the way in which we regulate the exhibition of other remedies. I have found no difficulty in accustoming the patient to the use and even enjoyment of the raw products to be described. Patients quickly overcome any preliminary distaste. When they realise the advantages of the treatment they take the raw meat with avidity.

From of exhibition. - It is usual to order it in one of three methods. 1. Pounded raw meat-i.e., finely minced or bruised beef slightly seasoned with salt, \&c.- - served natural, like mince collops, cold or gently warmed throughout. say from a quarter of a pound to half a pound twice or

1 A paper read before the International Congress on Tuberculosis held in Paris, Oct. 2nd-7th, 1905. 